\title{
Study on validity of a rapid diagnostic test kit versus light microscopy for malaria diagnosis in Ahmedabad city, India
}

S. Vyas, ${ }^{1}$ B. Puwar, ${ }^{1}$ V. Patel, ${ }^{1}$ G. Bhatt, ${ }^{2}$ S. Kulkarni ${ }^{3}$ and M. Fancy ${ }^{3}$

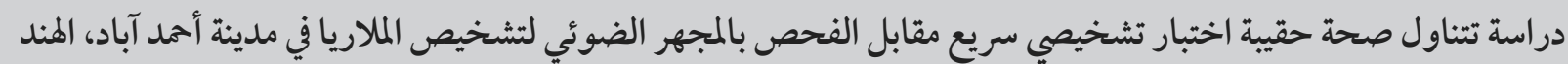

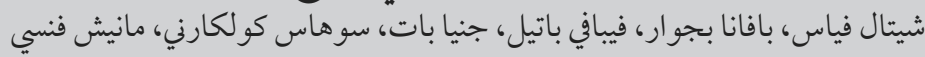

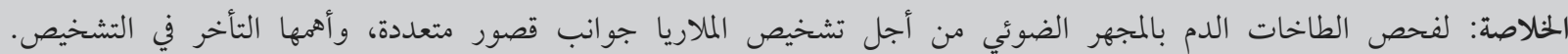

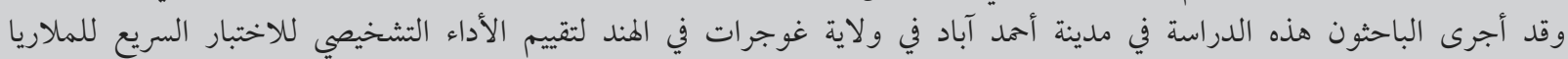

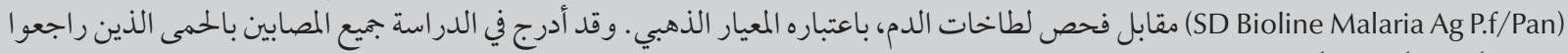

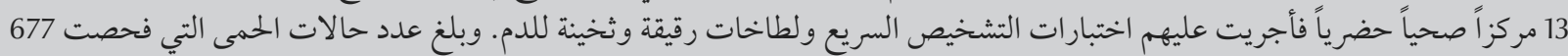

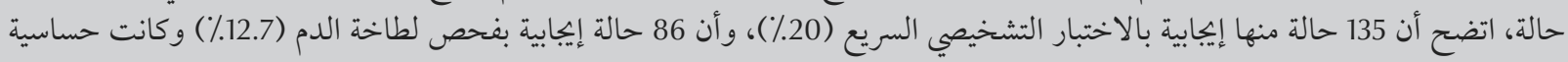

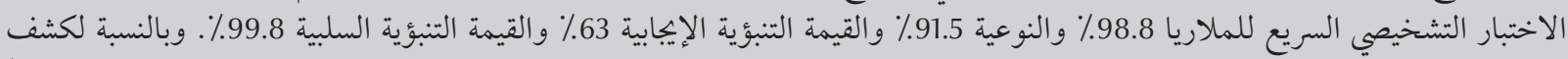

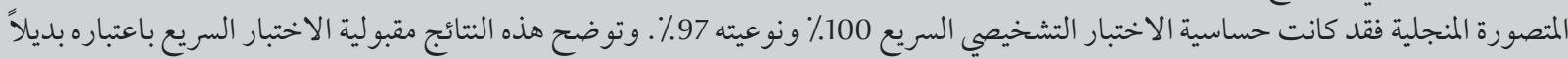

$$
\begin{aligned}
& \text { للفحص بالمجهر الضوئي في المواقع الميدانية. }
\end{aligned}
$$

ABSTRACT Light microscopy of blood smears for diagnosis of malaria in the field has several limitations, notably delays in diagnosis. This study in Ahmedabad in Gujarat State, India, evaluated the diagnostic performance of a rapid diagnostic test for malaria (SD Bioline Malaria Ag P.f/Pan) versus blood smear examination as the gold standard. All fever cases presenting at 13 urban health centres were subjected to rapid diagnostic testing and thick and thin blood smears. A total of 677 cases with fever were examined; 135 (20.0\%) tested positive by rapid diagnostic test and $86(12.7 \%)$ by blood smear. The sensitivity of the rapid diagnostic test for malaria was $98.8 \%$, specificity was $91.5 \%$, positive predictive value $63.0 \%$ and negative predictive value $99.8 \%$. For detection of Plasmodium falciparum the sensitivity of rapid diagnostic test was $100 \%$ and specificity was $97.3 \%$. The results show the acceptability of the rapid test as an alternative to light microscopy in the field setting.

Étude de la validité du kit de test de diagnostic rapide par rapport à l'examen microscopique pour le diagnostic du paludisme dans la ville d'Ahmedabad (Inde)

RÉSUMÉ L'examen microscopique des frottis sanguins pour le diagnostic du paludisme sur le terrain présente plusieurs limites, notamment les retards de diagnostic. La présente étude menée à Ahmedabad dans l'État de Gujarat (Inde) a évalué la performance diagnostique d'un test de diagnostic rapide du paludisme (SD Bioline Malaria Ag P.f/Pan) par rapport à l'examen d'un frottis sanguin en tant que méthode de référence. Tous les cas fébriles consultant dans un des 13 centres de soins urbains ont été soumis à un test de diagnostic rapide et à l'examen du frottis mince et de la goutte épaisse. Au total, 677 cas fébriles ont été examinés ; 135 (20,0 \%) étaient positifs par la méthode du test de diagnostic rapide et $86(12,7 \%)$ par la méthode du frottis sanguin. La sensibilité du test de diagnostic rapide pour le paludisme était de $98,8 \%$, la spécificité était de $91,5 \%$, la valeur prédictive positive de $63,0 \%$ et la valeur prédictive négative de 99,8\%. Pour le dépistage de Plasmodium falciparum, la sensibilité du test de diagnostic rapide était de $100 \%$ et la spécificité de $97,3 \%$. Les résultats démontrent l'acceptabilité du test de diagnostic rapide en tant qu'alternative à l'examen microscopique sur le terrain.

${ }^{7}$ Ahmedabad Municipal Corporation Medical Education Trust Medical College, Maninagar, Ahmedabad, India (Correspondence to S. Vyas: dr_shvyas@yahoo.com).2ujarat Medical Education and Research Society Medical College, Sola, Ahmedabad, India. ${ }^{3}$ Department of Health, Ahmedabad Municipal Corporation, Ahmedabad, India.

Received: 13/01/13; accepted: 02/06/13 


\section{Introduction}

Malaria is one of the major public health problems of India [1]. In Gujarat State, 71480 malaria cases were reported during 2012, 13.4\% of these due to Plasmodium falciparum [2]. In Ahmedabad, the largest city in Gujarat, the total number of malaria cases was 18802 , with $15.4 \%$ being P. falciparum cases. All clinically suspected malaria cases in India are subjected to blood smear examination, free of charge, by the public health system at the peripheral health centres in urban as well as rural areas. In addition, there are cadres offieldworkers in both urban and rural areas who carry out active surveillance for malaria by house-to-house visits and collection of blood smears for screening all clinically suspected malaria cases [3]. Nevertheless, the disease remains a major problem in certain states and geographical pockets.

When the results of blood smear examination by light microscopy are not available immediately, there can be a delay in the start of antimalarial treatment. This is especially serious in the cases of $P$. falciparum infection. Often presumptive treatment with chloroquine is offered to all fever cases due to lack of immediate availability of blood smear results. This is one of the reasons attributed to the rise in the proportion of $P$. falciparum cases and in resistance to chloroquine, which was previously used as the firstline treatment of malaria cases. Previous World Health Organization (WHO) guidelines were that treatment solely on the basis of clinical suspicion was to be considered only when a parasitological diagnosis was not accessible. Fears about the emergence of artemisininresistant strains of $P$. falciparum have led to a change in WHO policy to recommending restricting antimalarial treatment to laboratory-confirmed cases [4].

The development of rapid diagnostictests (RDTs), or dipsticks [5], tackles the most important limitation of blood smear examination, that results are not available immediately. RDTs, however, can be adopted as an alternative or additional diagnostic test only if all the validity indicators, especially sensitivity and specificity, are acceptable as compared with the existing screening test for malaria. In view of this, the present study was carried out in collaboration with Ahmedabad Municipal Corporation in Gujarat State to evaluate the diagnostic performance of a RDT against blood smear examination. The study was carried out before RDT was introduced as an alternative test along with the blood smear testing for diagnosis of malaria in active and passive surveillance of the disease in Ahmedabad city.

\section{Methods}

\section{Study setting and sample}

Ahmedabad city is the largest city of Gujarat State in India, with a population of 6 million, and is divided into 6 administrative zones: East, West, South, North, Central and New West, with a total of 57 urban health centres (UHCs). The study was carried out from August 2011 to November 2011, which corresponded to the high transmission season for malaria in Ahmedabad.

UHCs with a high malaria caseload were selected for inclusion in the study based on Ahmedabad Municipal Corporation records of fever cases in the year 2010. Two UHCs per zone were selected, making a total of 12 UHCs. The average proportion of fever cases in the last 2 years out of the total outpatient cases was $13 \%$ and by taking an allowable error of $20 \%$, the calculated sample size was 669 , which was equally distributed among the 12 UHCs. Based on this calculation, it was planned to recruit 56 fever cases from each UHC (a total of 672). However, as the caseload in one UHC was insufficient another was included in the study (i.e. a total of 13 UHCs). In practice, 677 fever patients were included in the study as all patients who reported with fever at the selected UHCs on the day of visit of the investigator team were included in the study.

\section{Data collection}

Each UHC was visited by the team of assistant professor and laboratory technician from the Department of Community Medicine at AMC Medical Education Trust Medical College. Information about patients' symptoms and other details was collected on a proforma. Each case of fever was subjected to both RDT and blood smear examination.

Blood specimens were collected from finger-prick using a sterile lancet by an experienced medical laboratory technician. As per the guidelines of the health department of Ahmedabad Municipal Corporation, thick and thin blood smears were prepared on the same slide and stained with field stain after fixing the thin smear with methanol. Smears were considered negative when no parasites are detected after examination of 100 microscopic fields. When thick smears were positive for parasites, Plasmodium spp. identification was done from the thin smears. Routinely, thick smears are examined under the microscope at the UHCs by their laboratory technicians. However, as a part of this project, laboratory technicians from the Department of Community Medicine performed RDT at the UHC, while the technician of the concerned UHC collected blood smears at the same time from the suspected malaria cases. For the purpose of confidentiality and blinding, these blood smears were not checked at the UHC but were checked by the technicians at the central laboratory of Ahmedabad Municipal Corporation, Kankaria.

The RDT kit used in the study was the SD Bioline Malaria Ag P.f/Pan (Standard Diagnostics) which could test both for $P$. vivax and P. falciparum malaria in finger-prick samples. These 2 species are prevalent in Gujarat. 
During the study, all the patients who tested positive for malaria by RDT kit were given treatment on the same day before the results of blood smear examinations were available from the central laboratory.

\section{Data analysis}

The data were entered into Microsoft Excel spreadsheets and were analysed using SPSS software, version 17.0. Calculation of frequencies, proportions, percentages, means, standard deviation (SD) and cross-tabulations and testing for significance were done as required. The following validity indicators for RDT were calculated taking blood smear examination as the gold standard: sensitivity, specificity, positive predictive value (PPV) and negative predictive value (NPV), accuracy, positive likelihood ratio $(\mathrm{LR}+)$ and negative likelihood ratio (LR-). These were done separately for malaria, for P. vivax malaria and for P. falciparum malaria.

Sensitivity was calculated as the proportion of positive test results against true positives $[\mathrm{TP} /(\mathrm{TP}+\mathrm{FN})]$; specificity was the proportion of negative test results against true negatives [TN/ $(\mathrm{TN}+\mathrm{FP})]$; PPV was the proportion of true positive results among all positively reacting samples $[\mathrm{TP} /(\mathrm{TP}+\mathrm{FP})]$; NPV was the proportion of true negative results among all negatively reacting samples, $[\mathrm{TN} /(\mathrm{TN}+\mathrm{FN})]$; and accuracy was $(\mathrm{TP}+\mathrm{TN}) /$ number of all tests, where $\mathrm{TP}=$ true positives, $\mathrm{FN}=$ false negatives, $\mathrm{TN}=$ true negatives and $\mathrm{FP}=$ false positives.

\section{Results}

\section{Demographic characteristics of fever cases}

Table 1 shows the demographic distribution of the 677 fever cases, by age, sex, residential zone, sleeping habits and use of personal protective equipment. The slide positivity rate (SPR) from blood

\begin{tabular}{|c|c|c|c|}
\hline Variable & $\begin{array}{c}\text { Total tested } \\
\text { No. }\end{array}$ & $\begin{array}{c}\text { SPR } \\
\%\end{array}$ & $P$-value ${ }^{a}$ \\
\hline \multicolumn{4}{|l|}{ Age (years) } \\
\hline$\leq 10$ & 110 & 9.1 & - \\
\hline $11-20$ & 177 & 8.5 & $>0.05$ \\
\hline $21-30$ & 134 & 10.4 & $>0.05$ \\
\hline $31-40$ & 105 & 15.2 & $>0.05$ \\
\hline $41-50$ & 81 & 18.5 & $>0.05$ \\
\hline $51-60$ & 44 & 27.3 & $<0.01$ \\
\hline$\geq 60$ & 26 & 15.4 & $>0.05$ \\
\hline \multicolumn{4}{|l|}{ Sex } \\
\hline Male & 372 & 14.8 & $>0.05$ \\
\hline Female & 305 & 10.2 & - \\
\hline \multicolumn{4}{|l|}{ Zone } \\
\hline North & 112 & 10.7 & $>0.05$ \\
\hline South & 112 & 29.5 & $<0.05$ \\
\hline Central & 112 & 11.6 & $>0.05$ \\
\hline East & 112 & 8.9 & $>0.05$ \\
\hline West & 112 & 8.0 & $>0.05$ \\
\hline New West & 117 & 7.7 & - \\
\hline \multicolumn{4}{|c|}{ Sleeping habits } \\
\hline Indoor & 642 & 12.3 & $>0.05$ \\
\hline Outdoor & 35 & 20.0 & - \\
\hline \multicolumn{4}{|c|}{ Use of personal protective equipment } \\
\hline Yes & 354 & 9.6 & $<0.05$ \\
\hline No & 323 & 16.1 & - \\
\hline Total & 677 & 12.7 & - \\
\hline
\end{tabular}

${ }^{a}$ Z-test.

smear examination was significantly higher in South zone, in the age group 51-60 years and for those not using personal protective equipment.

\section{Comparison of RDT and blood smear examination}

All 677 fever cases included in the study were subjected to both RDT and blood smear examination and the results were compared; 135 (20.0\%) fever patients tested positive for malaria by RDT whereas $86(12.7 \%)$ tested positive by blood smear examination (Table 2). Out of these 86 fever cases positive by blood smear, RDT was positive in 85 cases. Therefore RDT missed only 1 case of malaria which was diagnosed by blood smear examination.
Of the 135 patients testing positive by RDT, 100 were positive for $P$. vivax malaria, 6 for P. falciparum and 29 for both P. vivax and P. falciparum. Out of the 86 patients positive by blood smear, 69 were positive for P. vivax malaria and 17 for $P$. falciparum. Therefore, mixed infections with both $P$. vivax and P. falciparum were diagnosed only with RDT.

Out of all 129 patients who tested positive for P. vivax by RDT, 68 were positive for $P$. vivax both by RDT and blood smear examination, whereas 61 were positive by RDT but negative by blood smear. Of 35 cases positive for P. falciparum by RDT, 17 were also positive by blood smear examination 


\begin{tabular}{|c|c|c|c|}
\hline \multirow[t]{3}{*}{ Rapid diagnostic test result } & \multicolumn{2}{|c|}{ Blood smear results } & \multirow{3}{*}{$\begin{array}{l}\text { Total } \\
\text { No. }\end{array}$} \\
\hline & $+\mathbf{v e}$ & -ve & \\
\hline & No. & No. & \\
\hline \multicolumn{4}{|l|}{ Total malaria } \\
\hline +ve & 85 & 50 & 135 \\
\hline -ve & 1 & 541 & 542 \\
\hline Total & 86 & 591 & 677 \\
\hline \multicolumn{4}{|l|}{ All Plasmodium vivax } \\
\hline+ ve & 68 & 61 & 129 \\
\hline$-v e$ & 1 & 547 & 548 \\
\hline Total & 69 & 608 & 677 \\
\hline \multicolumn{4}{|l|}{ All Plasmodium falciparum } \\
\hline +ve & 17 & 18 & 35 \\
\hline -ve & 0 & 642 & 642 \\
\hline Total & 17 & 660 & 677 \\
\hline \multicolumn{4}{|l|}{ Mixed infection ${ }^{a}$} \\
\hline$+\mathrm{ve}$ & 0 & 29 & 29 \\
\hline -ve & 0 & 648 & 648 \\
\hline Total & 0 & 677 & 677 \\
\hline
\end{tabular}

a Both P. vivax and P. falciparum.

$+v e=$ positive $;-v e=$ negative .

whereas 18 were negative by blood smear.

\section{Validity indicators}

Validity indicators were calculated for RDT for diagnosis of malaria, $P$. vivax and $P$. falciparum separately, taking blood smear examination as the gold standard (Table 3 (The data of mixed infections were included with that of $P$. vivax and P. falciparum individually.)
The sensitivity of RDT for the diagnosis of malaria was 98.8\% (95\% CI: 93.7\%-99.8\%), for P. vivax malaria was 98.6\% (95\% CI: 92.2\%-99.7\%) and for P. falciparum malaria was $100.0 \%$ (95\% CI: $77.1 \%-100.0 \%)$. These were not statistically significantly different $(P>$ $0.05)$. The specificity of RDT for the diagnosis of P. falciparum (97.3\%; 95\% CI: 95.6\%-98.3\%) was significantly higher than for the diagnosis of any malaria (91.5\%; 95\% CI: $89.0 \%-93.5 \%)$ or of $P$. $\operatorname{vivax}(90.0 \%$; 95\% CI: 87.3\%-92.1\%) $(P<0.01)$.

The PPV for RDT for diagnosis of all malaria was 63.0\% (95\% CI: 54.6\%$70.6 \%$ ), and for P. vivax and P. falciparum was $52.7 \%$ (95\% CI: $44.1 \%-61.1 \%$ ) and $48.6 \%$ (95\% CI: $31.7 \%-65.7 \%$ ) respectively. These differences were statistically non-significant $(P>0.05)$. The NPV of RDT results for all malaria, $P$. vivax and $P$. falciparum were very high: 99.8\% (95\% CI: 99.0\%-100.0\%), 99.8\% (95\% CI: $99.0 \%-100.0 \%)$ and 100\% (95\% CI: 99.3\%-100.0\%) respectively, with no statistically significant difference between the 3 values $(P>0.05)$.

The LR+ for RDT was high and LR- was very low. Accuracy values for the test were high and there was good agreement between RDT and blood smear examination (Table 3).

The receiver operating characteristics curve was drawn for RDT, taking blood smear examination for malarial parasite as reference separately for diagnosis of malaria irrespective of species, P. vivax and P. falciparum and the area under the curve is shown in Figure 1.

\section{Discussion}

The present study assessed the performance of a RDT for detecting both $P$. vivax and P. falciparum infection versus light microscopy of thick and

\begin{tabular}{|c|c|c|c|}
\hline \multicolumn{4}{|c|}{$\begin{array}{l}\text { Table } 3 \text { Validity indicators for rapid diagnostic testing versus blood smear examination as the gold standard for detection of } \\
\text { malaria }\end{array}$} \\
\hline \multirow[t]{2}{*}{ Validity indicator } & Total malaria & Plasmodium vivax & Plasmodium falciparum \\
\hline & $\%(95 \% \mathrm{Cl})$ & $\%(95 \% \mathrm{Cl})$ & $\%(95 \% \mathrm{Cl})$ \\
\hline Sensitivity & 98.8 (93.7-99.8) & $98.6(92.2-99.7)$ & $100.0(77.1-100.0)$ \\
\hline Specificity & $91.5(89.0-93.5)$ & $90.0(87.3-92.1)$ & $97.3(95.6-98.3)$ \\
\hline PPV & $63.0(54.6-70.6)$ & $52.7(44.1-61.1)$ & $48.6(31.7-65.7)$ \\
\hline NPV & 99.8 (99.0-100.0) & 99.8 (99.0-100.0) & $100.0(99.3-100.0)$ \\
\hline Likelihood ratio (+ve) & $11.7(9.0-15.2)$ & $9.8(7.7-12.4)$ & $36.7(23.2-57.8)$ \\
\hline Likelihood ratio (-ve) & $0.013(0.002-0.089)$ & $0.016(0.002-0.113)$ & - \\
\hline Accuracy & 92.5 & 90.8 & 97.3 \\
\hline Карра & 0.73 & 0.64 & 0.64 \\
\hline
\end{tabular}

$C I=$ confidence interval; $P P V=$ positive predictive value, $N P V=$ negative predictive value $;+v e=$ positive $;-v e=$ negative.. 


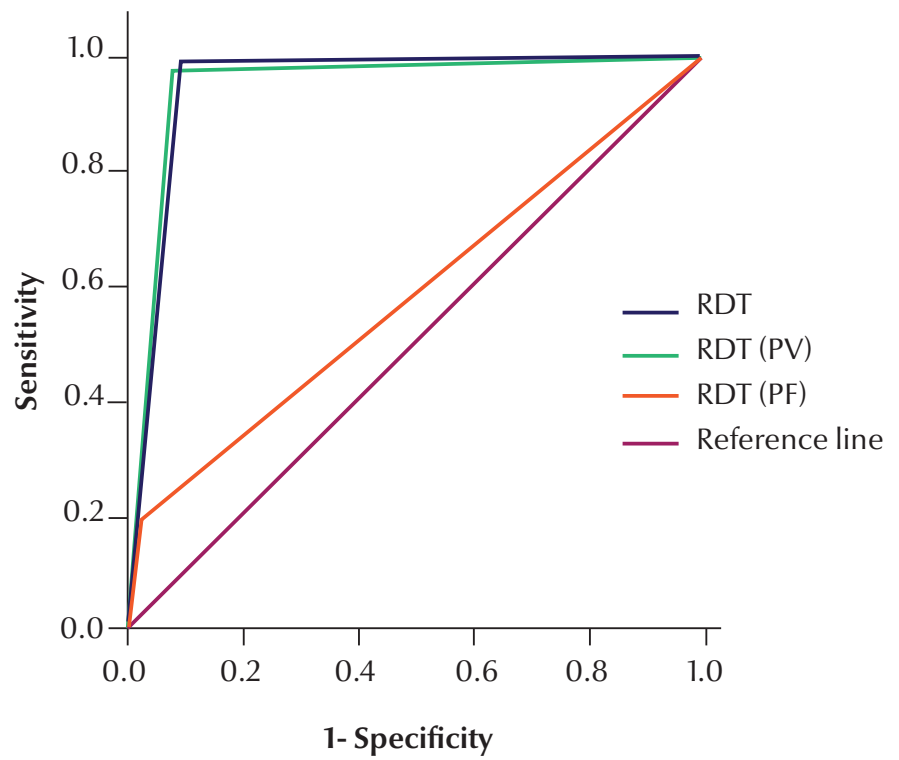

Figure 1 Area under the receiver operating characteristics (ROC) curve for rapid diagnostic test (RDT) of malaria versus blood smear examination as the gold standard. (Diagonal segments are produced by ties). PF = Plasmodium falciparum; PV = Plasmodium vivax

thin blood smears as the gold standard. The overall SPR was $12.7 \%$ among the fever cases included in the present study. The study period corresponded with the high transmission season for malaria in Ahmedabad city of India. This compares with the prevalence of uncomplicated malaria during the high transmission season in Tanzania, which was found to vary from $9.4 \%$ to $19.2 \%$ [6], whereas a rate of $22.6 \%$ was found in another study in Tanzania [7], 23.8\% in Ethiopia [8] and $31 \%$ also in Ethiopia [9].

The RDT identified more positive cases than the gold standard blood smear test $(20.0 \%$ versus $12.7 \%)$ and this was maybe due to persistently circulating antigen and prior use of antimalarial drugs $[3,4,7]$. The sensitivity of RDT for the diagnosis of malaria in the present study was $98.8 \%$ and the specificity was $91.5 \%$. These figures were similar to those found in several other studies [8,10-13], although in one study the sensitivity and specificity of RDTs compared with microscopy results were $85.3 \%$ and $59.8 \%$ respectively [ 7$]$.

The present study found the sensitivity and specificity of the RDT for P. falciparum malaria were $100.0 \%$ and $97.3 \%$ respectively. In another study in India by Neeru et al. the First Response combo RDT test was $94.7 \%$ sensitive (95\% CI: $89.5 \%-97.7 \%$ ) and $69.9 \%$ specific (95\% CI 63.6\%-75.6\%) for P. falciparum [12]. However, for non-falciparum infections the test was $84.2 \%$ sensitive (95\% CI: $72.1 \%-92.5 \%$ ) and $96.5 \%$ specific ( $95 \%$ CI: 93.8\%-98.2\%) [12]. Overall sensitivity of the SDFK90 rapid test for the detection of P. falciparum was $98.5 \%$ and specificity was $98.8 \%$ [11].

The PPV for malaria in the present study was $63.0 \%$ but was only $48.6 \%$ for P. falciparum. The PPV for P. falciparum in another study ranged between $63.1 \%$ and $70.9 \%$ [11].

In this study, the high LR+ and very low LR - of the RDT found for $P$. falciparum and $P$. vivax infections confirmed that patients with positive tests would have a high probability of being infected and patients with negative test would have high probability of not having infection. These findings agree with another study by Bendezu et al. [13]

\section{Conclusions}

The SD Bioline Malaria Ag P.f/Pan RDT performed well for the diagnosis of malaria. High sensitivity of malaria diagnosis is important in all settings and is essential for the most vulnerable population groups in which malaria infection produces an acute illness that can rapidly progress to death. Only microscopy and RDT are viable options at present in the field settings. The practical and speedy nature of RDTs makes them the only currently viable supplement to or replacement of microscopy-based diagnosis.

\section{Acknowledgements}

RDT kits were provided by the Department Health of Ahmedabad Municipal Corporation.

Competing interests: None declared.

\section{References}

1. World malaria report 2012. Geneva, World Health Organization, 2012 (WHO Global Malaria Programme) (www.who.int/ malaria/publications/world_malaria_report_2012/en/, accessed 22 November 2013)

2. Malaria situation in India. Delhi, Government of India, National Vector Borne Disease Control Programme [Internet] (http:// nvbdcp.gov.in/Doc/mal-situation-Sep13.pdf, accessed 22 November 2013).
3. Guidelines for diagnosis and treatment of malaria in India, 2010. Delhi, Government of India, National Vector Borne Disease Control Programme, 2010 (www.nvbdcp.gov.in/Doc/Technical-Guidelines-Malaria-2010.pdf. accessed 22 November 2013).

4. Guidelines for the treatment of malaria, 2nd ed. Geneva: World Health Organization, 2010 (http://whqlibdoc.who.int/publications/2010/9789241547925_eng.pdf, accessed 22 November 2013). 
5. Zhao J et al. Adoption of rapid diagnostic tests for the diagnosis of malaria, a preliminary analysis of the Global Fund program data, 2005 to 2010. PLoS ONE, 2012, 7:e43549.

6. Masanja IM et al. Increased use of malaria rapid diagnostic tests improves targeting of anti-malarial treatment in rural Tanzania: implications for nationwide rollout of malaria rapid diagnostic tests. Malaria Journal, 2012, 11:221.

7. Mubi $\mathrm{M}$ et al. Malaria rapid testing by community health workers is effective and safe for targeting malaria treatment: randomised cross-over trial in Tanzania. PLoS ONE, 2011, 6:e19753.

8. Endeshaw T et al. Performance of local light microscopy and the ParaScreen Pan/Pf rapid diagnostic test to detect malaria in health centers in Northwest Ethiopia. PLoS ONE, 2012, 7:e33014.

9. Mohammed $\mathrm{H}$ et al. Paracheck-pf ${ }^{\circledR}$ test versus microscopy in the diagnosis of falciparum malaria in Arbaminch Zuria Woreda of South Ethiopia. Ethiopian J ournal of Health Sciences, 2012, 22:93-98.
10. Batwala V, Magnussen P, Nuwaha F. Comparative feasibility of implementing rapid diagnostic test and microscopy for parasitological diagnosis of malaria in Uganda. Malaria Journal, 2011, $10: 373$.

11. Heutmekers $M$ et al. Evaluation of the malaria rapid diagnostic test SDFK90: detection of both PfHRP2 and Pf-pLDH. Malaria Journal, 2012, 11:359.

12. Singh $\mathrm{N}$ et al. Field and laboratory comparative evaluation of rapid malaria diagnostic tests versus traditional and molecular techniques in India. Malaria Journal, 2010, 9:191.

13. Bendezu J et al. Field evaluation of a rapid diagnostic test (Parascreen) for malaria diagnosis in the Peruvian Amazon. Malaria Journal, 2010, 9:154. 